\title{
Acellular dermal regeneration template for soft tissue reconstruction of the digits.
}

\author{
John S. Taras \\ Thomas Jefferson University \\ Anthony Sapienza \\ Thomas Jefferson University \\ Josh B. Roach \\ Thomas Jefferson University \\ John P. Taras \\ Thomas Jefferson University
}

Follow this and additional works at: https://jdc.jefferson.edu/orthofp

Part of the Orthopedics Commons, and the Surgery Commons

Let us know how access to this document benefits you

\section{Recommended Citation}

Taras, John S.; Sapienza, Anthony; Roach, Josh B.; and Taras, John P., "Acellular dermal regeneration template for soft tissue reconstruction of the digits." (2010). Department of Orthopaedic Surgery Faculty Papers. Paper 22.

https://jdc.jefferson.edu/orthofp/22

This Article is brought to you for free and open access by the Jefferson Digital Commons. The Jefferson Digital Commons is a service of Thomas Jefferson University's Center for Teaching and Learning (CTL). The Commons is a showcase for Jefferson books and journals, peer-reviewed scholarly publications, unique historical collections from the University archives, and teaching tools. The Jefferson Digital Commons allows researchers and interested readers anywhere in the world to learn about and keep up to date with Jefferson scholarship. This article has been accepted for inclusion in Department of Orthopaedic Surgery Faculty Papers by an authorized administrator of the Jefferson Digital Commons. For more information, please contact: JeffersonDigitalCommons@jefferson.edu. 


\author{
As submitted to: \\ Journal of Hand Surgery \\ And later published as: \\ “Acellular Dermal Regeneration Template \\ for Soft-tissue Reconstruction of the Digits" \\ Volume 35, Issue 3, March 2010, Pages 415-421 \\ DOI: 10.1016/j.jhsa.2009.12.008
}

\author{
John S. Taras, MD* \\ Anthony Sapienza, MD** \\ Josh B. Roach, DO** \\ Jack P. Taras**
}

(JST) Associate Professor, Jefferson Medical College of Thomas Jefferson University,

Philadelphia, PA; *Corresponding Author. The Philadelphia Hand Center, PC., 834 Chestnut

Street, Suite G-114, Philadelphia, Pennsylvania, 19107. Telephone (215) 521-3004; Fax (215)

629-0378; e-mail jstaras@handcenters.com

** The Philadelphia Hand Center, PC, 834 Chestnut Street, Suite G-114, Philadelphia,

Pennsylvania, 19107 
Key words: Acellular Dermal Regeneration Template (ADRT), Digit, Trauma, Soft-Tissue Defect, Soft-Tissue Coverage 


\title{
Acellular Dermal Regeneration Template for Soft Tissue Reconstruction of the Digits
}

\begin{abstract}
Purpose. Traumatic digit injuries often leave soft tissue defects with exposed bone, joint, and/or tendon requiring soft tissue replacement. The objective of this study was to evaluate the effectiveness of acellular dermal regeneration template (ADRT) combined with full-thickness skin grafting for soft tissue reconstruction in digit injuries with soft tissue defects.
\end{abstract}

Methods. ADRT was used to reconstruct digit injuries with exposed bone, joint, tendon, and/or hardware not amenable to treatment with healing by secondary intention, rotation flaps, or primary skin grafts. ADRT was applied to 21 digits in 17 patients. Nineteen digits had exposed bone; 8 digits had exposed tendon; 6 digits had exposed joints; and 2 digits had exposed hardware. The ADRT was sutured over the soft tissue defect. Over 3 weeks, a neodermis formed. The superficial silicone layer of the ADRT was removed, and the digits underwent fullthickness epidermal autografting with cotton bolster.

Results. The duration of postoperative follow-up extended to a minimum of 12 months. For the injury sites where ADRT was applied, the total area of application ranged from 1 to $24 \mathrm{~cm}^{2}$, with the largest individual site measuring $12 \mathrm{~cm}^{2}$. Twenty of 21 digits demonstrated $100 \%$ incorporation of the ADRT skin substitute. One digit that had sustained multi-level trauma developed necrosis requiring revision amputation. Full-thickness epidermal autografting was performed an average of 23.9 days after ADRT skin substitute application and demonstrated a 
$100 \%$ take in 16 of $20(80 \%)$ digits and partial graft loss of 15 to $25 \%$ in 4 of $20(20 \%)$ digits that did not require further treatment.

Conclusions. ADRT combined with secondary full thickness skin grafting is an effective method of skin reconstruction in complex digital injuries with soft tissue defects involving exposed bone, tendon, and joint. The neodermis increases tissue bulk and facilitates epidermal autografting with digital injuries that otherwise would require flap coverage or skeletal shortening of the digit.

\section{Introduction}

Traumatic injuries of the digits often leave extensive soft tissue defects with exposed bone, tendon, and/or joints requiring soft tissue coverage. There are a multitude of treatment options for distal digit injuries with skin loss, including wound care allowing wound contracture without a surgical procedure, skeletal shortening and primary closure, split or full-thickness skin grafting, and local, regional, and distal flaps. Classic teaching advocates that injuries with exposed bone lacking periosteum, exposed joint surfaces, or with exposed tendon lacking paratenon must have bone trimmed back to allow closure by the surrounding tissues or undergo coverage with a vascularized flap., 2, 3,4 Exposed bone, tendon, or cartilage does not have sufficient blood supply to support a granulation bed necessary for rapid reepithelialization. Exposed bone and associated fractures run the risk of desiccation and infection unless they are sufficiently covered by soft tissue. Likewise, the neovascularization necessary for the survival of a skin graft is also dependent on the blood supply of the underlying tissue. The geometry of the digit injury (transverse, volar/dorsal/lateral oblique) in distal tissue loss can also guide treatment options. Local, regional, and distal flaps have been commonly advocated when there is inadequate soft tissue to cover exposed bone and tendon and skeletal shortening is not desired. 
Local rotation type flaps in the digits can be limited by the amount of soft tissue they can replace. Regional and distal flaps require an awkward positioning of the donor and recipient sites for the 2 weeks required for vascularization of the flap from the recipient site. These flaps can often transfer more soft tissue than was originally lost necessitating a later debulking procedure. Injury that involves the distal phalanx may result in a secondary hook-nail deformity if there is unsupported nailbed, which can be accentuated by skeletal shortening of the distal phalanx in order to eliminate exposed bone in a wound. ${ }^{2,3}$ These deformities are not only cosmetically unappealing but also functionally undesirable since the nail can prove a nuisance by snagging on clothing and other objects. A deformity can be minimized if the nailbed is at least $2 \mathrm{~mm}$ proximal to the underlying bone. ${ }^{5}$ Loss of volar oblique and even lateral oblique amputations can increase the risk of developing a deformity if care is not taken in restoring the soft tissue defect. A hook-nail deformity may occur if unnecessary tension is placed on adjacent tissues during wound closure of a fingertip amputation.

Treatment goals in digital injuries include preservation of functional length, preservation of useful sensation and prevention of painful neuromas, provision of durable skin coverage, early mobilization and prevention of joint contractures, early return of function, and providing for a cosmetically appealing appearance..$^{2,3,6,}$ The treatment options for soft tissue loss of the digits become more limited once bone, joint, and tendon are exposed. The common solutions have been either skeletal shortening to facilitate soft tissue closure or application of a wide variety of vascularized skin flaps.

The most commonly used regional flaps for soft-tissue coverage in the digits are the cross-finger pedicle flap ${ }^{7}$ and the thenar flap.8, 9, 10 Both flaps are used for coverage of volar skin loss of the digits with the thenar flap reserved for distal coverage of the index and long fingers. Some surgeons reserve the thenar flap for young females because this flap requires more flexion of the injured finger until flap division, thus, having a theoretic risk of flexion contracture. ${ }^{2}$ 
Melone $^{9}$, however, showed that by detatching the pedicle by $10-14$ days persistent contracture was low.

Acellular dermal regeneration template (ADRT) has been demonstrated to be an effective skin substitute for burn patients and a useful tool to reconstruct complex full-thickness

wounds. ${ }^{11,12,13}$ This report details our experience with ADRT for the treatment of traumatic digit injuries. The template (Integra® Dermal Regeneration Template, Integra LifeSciences, Inc. Plainsboro, $\mathrm{NJ}$ ) consists of a bilaminate sheet that allows for the establishment of a neodermis while providing a semipermeable membrane to maintain a moist healing environment. The thin superficial polysiloxane layer serves as an artificial epidermis. The deeper porous layer of cross-linked bovine tendon collagen and chondroitin-6-sulfate allows the migration of fibroblasts to regenerate a dermis. After a period of 21 days epidermal autografting of the neodermis can be performed. Recent case reports have documented excellent results with the use of ADRT for reconstruction after tumor excision from the hand, a degloving injury involving the lower extremity, and in traumatic combat injuries. ${ }^{14,15,16}$

The application of ADRT for traumatic digit injuries involving exposed bone, tendon, or joint has not been extensively documented. This prospective study describes the use of ADRT in 17 consecutive patients to treat 21 traumatic digit injuries that otherwise would have required more elaborate reconstructive procedures. All cases presented with exposed bone, tendon, or joint, precluding treatment by dressing changes possibly followed by skin grafting. One benefit of ADRT is that it provides the structural scaffold for vascular and cellular ingrowth while providing a protective barrier for the exposed bone, joint, and tendon when simpler techniques cannot cover the exposed deep structures.

\section{Materials and Methods}

Seventeen patients (average age 38.6 years, range 21 to 63 years) were treated with 21 applications of Integra® Dermal Regeneration Template for soft tissue loss in the digits. (Integra 
LifeSciences, Inc. Plainsboro, NJ) All of the cases were the result of trauma except for 1 case that was due to necrosis after an infection of a skin laceration. Of the 21 injured digits, 14 (66.7\% of total injuries) suffered digital amputation injuries. Of the 14 amputations, 2 digits (9.5\% of total injuries) had failed fingertip coverage with composite grafts from the amputated part, 8 digits (38.1\% of total injuries) suffered skin degloving injuries, and 1 (4.8\% of total injuries) digit required extensive debridement after developing skin necrosis from an infected laceration. Nineteen digits had exposed bone; 8 digits had exposed tendon; 6 digits had exposed joints (3 metacarpophalangeal (MCP) joints, 3 proximal interphalangeal (PIP) joints, 3 distal interphalangeal (DIP) joints); and 2 digits had exposed hardware.

Inclusion criteria comprised digit injuries that resulted in soft tissue loss with exposed underlying bone, joint, hardware, and/or tendon (Fig. 1). These were injuries in which the loss of local tissue precluded definitive treatment by simple wound care, primary closure, skin graft, or a simple rotation flap and where more elaborate reconstructive techniques were deemed necessary. None of the cases that presented were felt to have been amenable to healing by secondary intention or primary skin grafting. Patients were offered the most appropriate alternate regional flap (thenar, cross-finger, or pectoral flap, and in one case ray resection). During the case collection period, no patient chose alternate treatment by regional or distant flaps or digital shortening or deletion. Patients were not excluded because of demographic parameters that may have compromised wound healing such as age, diabetes, or smoking. Use of a control group was not included in this study of the efficacy of the ADRT product. Historical data was used as a control reference due to the limited sample size available for the study.

Each patient underwent 2 separate procedures in the operating room. The initial procedure involved wound irrigation, debridement, and application of ADRT. The total area of ADRT placed and the percentage of the wound bed that was adequately repaired by the ADRT to accept the skin graft was recorded. After approximately 3 weeks, patients returned to the 
operating room to undergo a second procedure for full-thickness skin grafting. Before application of the ADRT, 13 patients underwent irrigation and debridement in the emergency room setting, 2 patients underwent fingertip composite grafting of the amputated part in the operating room setting, and 2 patients underwent irrigation and debridement in both the emergency room and the operating room for grossly contaminated wounds.

Acellular dermal regeneration template was measured in $\mathrm{cm}^{2}$ at the initial operative procedure. The amount of ADRT used was directly proportional to the size of the wound. The template was attached to the wound edge and secured with 4-O nylon suture sewn in interrupted fashion (Fig. 2) For larger defects, the superficial silicone layer was darted to allow for fluid egress from the wound bed and to facilitate ADRT graft adherence. Between ADRT application and skin grafting, the patients were instructed in a home exercise program with mobilization exercises of the unaffected joints while protecting the ADRT site with a thermoplastic splint between exercise periods. At the second procedure, the superficial silicone covering was removed in the operating room by gently peeling it off. The template vascularization rate was then estimated based on clinical examination and by measuring the percentage of total wound surface area covered with neodermis. Full-thickness skin grafting was performed with hypothenar, antecubital fossa, or volar wrist crease donor graft. Patients were followed on an outpatient basis until all wounds demonstrated complete epithelialization and then at 12 months to assess range of motion and sensibility (Fig 3). Successful implementation of ADRT was determined by a composite of the data regarding preservation of functional length, preservation of useful sensation, provision of durable skin coverage, early mobilization of injured joints aiding in and prevention of joint contractures, early return to work and other activities, and good cosmetic appearance of the digit.

Patients were analyzed with respect to age, past medical history, injury location and cause, presence of exposed structures in the wound, and whether the injury was work related. Wound healing complications, cold intolerance, sensitivity, sensibility, and digital motion were 
recorded. Postoperatively, a dichotomous data survey was employed in which patients responded yes or no during physical examination of the affected digit(s) to evaluate for hypersensitivity and/or hyposensitivity. Objective measures of sensory discrimination including static and moving 2-point discrimination were not employed because of the incongruent nature and size of the wound sites, making this testing not uniformly applicable. The patient was asked to judge sensation of the graft as being less than $33 \%$ of normal, between $33 \%$ and $66 \%$ of normal, or greater than $66 \%$ of normal. The time intervals between injury and ADRT application and ADRT application and skin graft were recorded. The total area of ADRT placed and the percentage of the wound bed that was adequately repaired by the ADRT to accept the skin graft were documented.

Results. Patients were followed for a minimum of 12 months (range, 12 - 22 months) except for the patient having necrosis of the digit who was dismissed. The total area of ADRT application ranged from $1 \mathrm{~cm}^{2}$ to $24 \mathrm{~cm}^{2}$, the largest single site measuring $12 \mathrm{~cm}^{2}$. All digits demonstrated $100 \%$ vascularization of the ADRT dermal substitute with the exception of one digit that had sustained a multi-level crush injury requiring amputation after application of ADRT due to digit necrosis. ADRT placement was performed an average of 5.9 days (range, $3-12$ days) after injury, and full-thickness epidermal autografting was performed an average of 23.9 days (range, 14 - 35 days) after ADRT skin substitute application and demonstrated 100\% incorporation in 16 of 20 digits and $15-25 \%$ partial graft loss in 4 of 20 digits that did not require further treatment. Thus, $80 \%$ of injury sites demonstrated complete skin graft success and $20 \%$ of injury sites demonstrated minor skin graft loss. The ADRT with full thickness skin grafting was found to be adherent and stable with patients having demonstrated no wound breakdown after reaching maximum medical improvement.

Four of 20 digits (20\%) demonstrated eschar formation with partial skin graft loss but did not require further surgical reconstruction. A minor portion of the skin graft was avulsed in 2 
digits with subsequent readherence of the tissue, emphasizing the importance of maintaining a protective cap splint during graft incorporation. Both of these digits went on to $100 \%$ incorporation of the skin graft sites.

Eleven patients sustained their 12 digital injuries while working. All of these patients ultimately returned to work, but 3 patients had a permanent partial disability that required an alteration in their work duties.

At final follow-up all 20 surviving digits were found to have stable wound coverage without episodes of wound breakdown. Two digits were reported as having moderate cold sensitivity. All of the skin grafts were noted to have altered sensation; 3 of the skin grafts were felt to have had less than $33 \%$ of normal sensation, 15 skin grafts had between $33-66 \%$ of normal sensation, and 2 skin grafts had greater than $66 \%$ of normal sensation. Two digits were reported as having persistent hypersensitivity at the graft site. Full recovery of range of motion was found in the 15 digits not having sustained a significant concomitant joint injury. Two digits had intraarticular PIP joint fractures resulting in a $15^{\circ}$ PIP joint flexion contracture in one digit, and a loss of flexion of $1 \mathrm{~cm}$ to the distal palmar crease in the other; and 1 patient with 3 injured digits had arthrodesis of 3 DIP joints and 1 PIP joint due to extensive articular damage but returned to work as an intensive care unit nurse.

None of the injured digits in the study developed a secondary hook-nail deformity. The skin graft recipient sites were divided into 2 sample groups: those with $100 \%$ incorporation and those with partial loss. An independent groups T-test for means showed that there was no statistical significance for age, graft size, or number of irrigations with regard to graft take. Two of the 4 digits with partial skin graft incorporation occurred in patients with a known history of diabetes mellitus; 1 patient was also a smoker. None of the 16 digits with $100 \%$ skin graft incorporation occurred in patients who had a history of diabetes mellitus and/or smoking. A Z-test for two proportions failed to demonstrate a statistical significance between 
smokers and non-smokers regarding graft incorporation but did demonstrate a difference between diabetics and non-diabetics with $98 \%$ confidence.

\section{Discussion}

Treatment options are varied when traumatic digit injuries are accompanied by loss of soft tissue and exposure of underlying bone and joints. Jebson and Louis ${ }^{2}$ note that treatment of similar injuries by widely disparate methods likely reflect varied exposure to techniques during training combined with the experience gaining in treating such injuries. Numerous types of flap procedures have been described to reconstruct digital defects such as the Kutler and Atasoy VY advancement flaps ${ }^{1}$, thenar flap ${ }^{8,9,10}$, and cross finger flap ${ }^{7}$. These procedures can be associated with donor site morbidity including contour deformity and dysesthesias. ${ }^{1,17,18}$ After reviewing several follow-up studies of adult patients having sustained fingertip injuries with pulp loss, Jebson and Louis concluded that $30 \%$ to $50 \%$ of patients complained of some cold intolerance and an approximately $30 \%$ chance of having some aberration in sensibility, regardless of which wound management technique was used, and that these features appear to be the consequence of the injury itself and not the treatment. ${ }^{1,17,18}$ Ideal soft tissue coverage for fingertip injuries should provide durable protection with adequate soft tissue bulk.

An innovative approach to reconstruct soft tissue defects after a traumatic digital injury involves the use of ADRT. The focus of this paper was to assess stability of the wound coverage. This template has been reported to be an effective skin substitute for thermal injuries and complex full-thickness wounds. ${ }^{11,12,13}$ It provides the ability to cover large soft tissue defects while eliminating the donor site morbidity of flaps, limiting scar formation and wound contracture. $^{19,20,21,22,23}$ ADRT is approved for treatment of full-thickness thermal injuries and scar reconstruction.

The template consists of a bilaminate membrane that allows the graft site to form a neodermis while providing a semipermeable membrane to maintain a moist healing 
environment. A superficial thin polysiloxane layer serves as an artificial epidermis. The porous surface of cross-linked bovine tendon collagen and chondroitin-6-sulfate allows the migration of fibroblasts to regenerate a dermis. The neodermis is histologically similar in structure and appearance to normal dermis. ${ }^{24,25}$ Myofibroblasts are inhibited from migration, thus, preventing scar contraction. By 14-21 days, a neodermis forms and the silicone superficial covering can be removed. The wound can then be treated in various ways depending on the reconstructive needs of the patient. For a small surface area defect, the wound can autoepithelialize or a thin split-thickness skin graft (0.006 inch) can be applied. This allows for decreased donor site morbidity and the ability to reuse donor sites. For other wounds, a standard split-thickness skin graft (0.010 - 0.015 inch) or a full-thickness skin graft can be applied. In this study, a fullthickness skin graft from hypothenar, antecubital fossa, or volar wrist crease donor sites was applied. The full-thickness graft was felt to provide enhanced bulk for durable coverage of underlying bone, joint, and/or tendon. ${ }^{26}$

The use of ADRT for traumatic hand injuries, particularly its application directly over exposed bone, joint, or tendon, is not well-documented. Lozano reported on the use of ADRT for repair of a lower extremity degloving injury. He reported its use as an alternative to flap coverage preventing a below-knee amputation from requiring flap coverage or conversion into an above-knee amputation. ${ }^{14}$ Carothers et al. reported on the use of ADRT for reconstruction of a soft tissue defect after tumor excision from the palm of the hand. In their case report, 2 sheets of ADRT were stacked directly over a wound bed with exposed flexor tendons and median nerve. They reported full functional use of the hand with mild paresthesias and no adhesions of the flexor tendons underlying the ADRT. They speculated that the favorable immunologic response of host tissue to the bovine matrix might have protected underlying structures from incorporation into the overlying scar tissue. ${ }^{15}$ Helgeson et al. reported on the use of ADRT in the management of complex combat-related soft tissue wounds. Their series involved application of ADRT to 4 feet, 6 legs, 2 thighs, 1 hip, 1 shoulder, and 2 forearm 
wounds. Eleven of the wounds had exposed tendon and 5 had exposed bone. Following Integra® Dermal Regeneration Template grafting, all of the wounds were managed with vacuum-assisted closure (VAC) dressings followed by delayed split-thickness skin grafting. Thirteen of 16 wounds achieved definitive coverage on initial application. All 3 failures involved exposed cortical bone without periosteum, but repeat ADRT grafting proved successful in 2 of the 3 failures. ${ }^{16}$

In this study, there were no exclusion criteria; therefore, patient factors that may have inhibited healing such as smoking and diabetes mellitus were included. It is conceivable that revascularization of the ADRT and/or the full-thickness skin graft could be inhibited by these factors. From the limited sample size, it was difficult to determine the statistical significance that diabetes mellitus and/or smoking would have on graft outcome. All of the patients with $100 \%$ take of their graft sites had no history of diabetes mellitus and/or smoking. In contrast, 2 of the 4 graft sites with partial take occurred in patients with a known history of diabetes mellitus, and 1 patient was also a smoker.

Although the sample size of the current study was limited, we were able to meet our principle objective in demonstrating ADRT to be an effective skin substitute in complex digit injuries with soft tissue defects not amenable to treatment with healing by secondary intention or primary grafting. In this series, application of ADRT with subsequent skin grafting provided an alternative to flap coverage for traumatic digit injuries with exposed bone, joint, and/or tendon. A $2 \times 2 \mathrm{~cm}$ piece of ADRT costs approximately $\$ 1,240$ USD at our institution and requires 2 surgical procedures, but the considered other treatment options of regional flaps require 2 surgical procedures as well. Application of ADRT and full-thickness skin grafting allows mobilization of uninjured joints facilitating recovery, whereas, regional or distant flaps greatly restrict mobilization of the uninjured joints, while patients undergoing ADRT treatment for injuries involving composite tissue loss over joint surfaces had loss of joint motion as would be expected regardless of the treatment. As direct comparison with vascularized flaps was not 
done in this series, it remains unclear whether a vascularized flap would have provided a more compliant soft tissue coverage. Porter ${ }^{26}$ compared pedicle flaps to skin grafts for volar skin defects of the digits and concluded that cross finger and thenar flaps had the best cosmetic appearance and sensibility with pectoral flaps fairing less well, and that full thickness skin grafts were superior to split grafts in terms of durability. Negative pressure dressings have become a major first line of treatment for orthopedic extremity trauma including wounds with exposed bone, but no reports of its use in isolated digital injuries are to be found, although its use was reported as assisting in the treatment of a degloved hand. ${ }^{27,28}$

Patients, when informed of regional or distant flap alternatives, appeared to find treatment by ADRT and skin graft the more appealing option. Future studies will hopefully expand the application of ADRT to include more complex digital and hand injuries and determine which patient population(s) would be the best candidates for ADRT and subsequent skin grafting. 


\section{Figure Legend}

Figure 1: A 30-year-old right-hand-dominant male retired NFL football player sustained amputations of the thumb and ring finger from a power saw. He also sustained lacerations to the index and long digits with underlying distal phalanx fractures.

Figure 2: $\quad$ After irrigation and debridement, the ADRT was secured to the skin with interrupted 4-O Nylon suture.

Figure 3: $\quad(\mathrm{A}, \mathrm{B})$ The patient demonstrated excellent healing--- after full thickness skin graft, as seen here for follow-up on postoperative day 53. He reported near normal sensation at the tip of his thumb and mildly diminished sensation on the dorsum of his ring finger. 


\section{References}

${ }^{1}$ Mathes SJ. Plastic surgery. 2nd ed. Vol. 7. Philadelphia: WB Saunders, 2005:153-170.

${ }^{2}$ Jebson PJL and Louis DS. Amputations. In Green DP, Hotchkiss RN, Pederson WC, Wolfe SW. Green's Operative Hand Surgery, 5th ed. Elsevier: Churchill Livingstone, 2005. 1939-1950.

${ }^{3}$ Wittstadt RA. Treatment options for distal tip amputations. In Strickland JW, Graham TJ, ed. Masters Techniques in Orthopaedic Surgery: The Hand. 2nd ed. Philadelphia: Lippincott Williams \& Wilkins, 2005: 323-338.

${ }^{4}$ Pederson WC and Lister G. Skin flaps. In: Green DP, Hotchkiss RN, Pederson WC, and Wolfe SW. (eds) Green's Operative Hand Surgery (ed5). Philadelphia: Elsevier, 2005. pp. 16481704.

${ }^{5}$ Dumontier C. Distal replantation, nail bed, and nail problems in musicians. Hand Clinics 2003;19:259-272.

${ }^{6}$ Chang J, Vernadakis AJ, McClellan WT. Fingertip Injuries. Clin Occup Environ Med. 2006; $5(2): 413-422$.

${ }^{7}$ Gurdin M, Pangman WJ: The repair of surface deficits of fingers by transdigital flaps. Plast Reconstr Surg 5:368-371, 1950.

${ }^{8}$ Gatewood A: A plastic repair of finger defects without hospitalization. JAMA 87:1479, 1926.

${ }^{9}$ Melone CP, Beasley RW, Carstens HJ: The thenar flap: An analysis of its use in 150 cases. J Hand Surg [Am] 7:291-297, 1982.

${ }^{10}$ Smith RJ, Albin R: Thenar "H-flap" for fingertip injuries. J Trauma 16:778-781, 1976.

${ }^{11}$ Molnar JA, DeFranzo AJ, Hadaegh A, Morykwas MJ, Shen P, Argenta LC. Acceleration of Integra incorporation in complex tissue defects with subatmospheric pressure. Plast Reconstr Surg 2004;113:1339-1346. 
${ }^{12}$ Heimbach D, Luterman A, Burke J, Cram A, Herndon D, Hunt J, et al. Artificial dermis for major burns: a multi-center randomized clinical trial. Ann Surg 1988;208:313-319.

${ }^{13}$ Burke JF, Yannas IV, Quimby WC, Bondoc CC, Jung WK. Successful use of a physiologically acceptable artificial skin in the treatment of extensive burn injury. Ann Surg $1981 ; 194: 413-428$.

${ }^{14}$ Lozano $\mathrm{D}$. The use of a dermal regeneration template for the repair of degloving Injuries: a case report. Wounds 2003;15(12):395-398.

${ }^{15}$ Carothers JT, Brigman BE, Lawson RD, Rizzo M. Stacking of a dermal regeneration template for reconstruction of a soft tissue defect after tumor excision from the palm of the hand: a case report. J Hand Surg 2005;30A(6):1322-1326.

${ }^{16}$ Helgeson M, Potter B, Evans K, Shawen S. Bioartificial dermal substitute: a preliminary report on its use for the management of complex combat-related soft tissue wounds. J Ortho Trauma. 2007;21(6):394-399.

${ }^{17}$ Russell RC, Casas LA. Management of fingertip injuries. Clin Plast Surg 1989;16:405-425.

${ }^{18}$ Hart R, Kleinert H. Fingertip and nail bed injuries. Emerg Med Clin North Am 1993;11:755765.

${ }^{19}$ Abai B, Thayer D, Glat PM. The use of a dermal regeneration template (Integra) for acute resurfacing and reconstruction of defects created by excision of giant hairy nevi. Plast Reconstr Surg 2004;114(1):162-168.

${ }^{20}$ Dantzer E, Queruel P, Salinier L, Palmier B, Quinot JF. Dermal regeneration template for deep hand burns: clinical utility for both early grafting and reconstructive surgery. $\mathrm{Br} \mathrm{J}$ Plast Surg 2003;56(8):764-774.

${ }^{21}$ Wolter TP, Noah EM, Pallua N. The use of Integra in an upper extremity avulsion injury. Br J of Plast Surg 2005;58(3):416-418. 
${ }^{22}$ Silverstein G. Dermal regeneration template in the surgical management of diabetic foot ulcers: a series of five cases. J Foot Ankle Surg 2006;45(1):28-33.

${ }^{23}$ Klein MB, Engrav LH, Holmes JH, Friedrich JB, Costa BA, Honari S, et al. Management of facial burns with a collagen/glycosaminoglycan skin substitute-prospective experience with 12 consecutive patients with large, deep facial burns. Burns 2005;31(3):257-261.

${ }^{24}$ Moiemen NS, Staiano JJ, Ojeh NO, Thway Y, Frame JD. Reconstructive surgery with a dermal regeneration template: clinical and histologic study. Plast Reconstr Surg 2001;108:93-103.

${ }^{25}$ Stern R, McPherson M, Longaker MT. Histologic study of artificial skin used in the treatment of full-thickness thermal injury. J Burn Care Rehab 1990;11:7-13.

${ }^{26}$ Porter RW. Functional assessment of transplanted skin in volar defects of the digits: a comparison between free grafts and flaps. J Bone Joint Surg 1968;50A:955-963.

${ }^{27}$ DeFranzo AJ, Marks MW, Argenta LC and Genecov DG. Vacuum-assisted closure for the treatment of degloving injuries. Plast Reconstr Surg 1999;104(7), 2145-2148.

${ }^{28}$ Argenta LC, Morykwas MJ, Marks MW, DeFranzo AJ, Molnar JA, David LR. Vacuum-assisted closure: state of clinic art. Plast Reconstr Surg. 2006; 117(7S), 127S-142-S. 